\title{
Ohmic contacts on sputtered a-Si : H
}

\author{
J. C. Bruyère and A. Deneuville \\ Groupe des Transitions de Phases (*), C.N.R.S., B.P. 166, 38042 Grenoble Cedex, France
}

(Reçu le 28 août 1979, révisé le 9 novembre, accepté le 29 novembre 1979)

\begin{abstract}
Résumé. - Nous montrons que des contacts ohmiques sont obtenus par pompage d'hydrogène contenu dans les films a-Si: $\mathrm{H}$. Ces contacts ohmiques sont réalisés après diffusion de l'hydrogène dans les films adjacents de la structure tels que le « a-Si » à $190^{\circ} \mathrm{C}$ ou le « $\mathrm{Pd}$ » à température ambiante.
\end{abstract}

\begin{abstract}
We show that ohmic contacts can be obtained by hydrogen depletion in a-Si : $\mathrm{H}$. We obtain these ohmic contacts by diffusion of hydrogen into adjacent films of pure a-Si at $190^{\circ} \mathrm{C}$ or $\mathrm{Pd}$ at room temperature.
\end{abstract}

Following the work of the Dundee [1] and R.C.A. [2] groups, several laboratories have tried to use a-Si $: \mathrm{H}$ in thin films devices $[2,3]$. This requires good ohmic contacts. Also, if the band bending near the surfaces found by Solomon et al. [4] for glow discharge material is quite general, an unambiguous determination of the electrical conductivity and its activation energy (in particular for intrinsic a-Si : $\mathrm{H}$ ) has to be carried out for sandwich structures and so also needs good ohmic contacts.

Until now, only highly doped a-Si : $\mathrm{H}$ has been systematically used as an ohmic contact in sandwich structure devices $[2,3]$ by transposition of the crystalline device results, although such a behaviour is not generally demonstrated and is at least restricted to $E<10^{4} \mathrm{~V} \mathrm{~cm}$.

We follow here a completely different approach, derived from a comparison between a-Si and a-Si : $\mathrm{H}$ properties. Pure amorphous silicon a-Si has a large density of localized states in its forbidden gap, for instance dangling bonds [5] acting as recombination centres. Consequently, this material cannot be doped or exhibit a space charge zone. The addition of a sufficient amount of hydrogen to this silicon matrix gives a-Si : $\mathrm{H}$ where the density of localized states (especially that of dangling bonds) is sufficiently low to allow the doping [1] and the existence of a significant space charge zone [2]. We thought that a good ohmic contact might be achieved by a gradual transition from a-Si : $\mathrm{H}$ towards a-Si, i.e. by decreasing continuously the hydrogen density in a-Si $: \mathrm{H}$ down

$\left(^{*}\right)$ Laboratoire associé à l'Université Scientifique et Médicale de Grenoble. to a sufficiently low level. Although many methods may be used, we describe here two simple ways by which hydrogen from sputtered a-Si : $\mathrm{H}$ films is removed by the contiguous films.

The films are deposited by R. F. diode cathodic sputtering of a $\mathrm{Si}$ target in an argon (a-Si) or $20 \%$ $\mathrm{H}_{2} / 80 \%$ Ar (a-Si : $\left.\mathrm{H}\right)$ gas $\left(9 \times 10^{-3}\right.$ torr $)$ at deposition rates of $70 \AA / \mathrm{min}$. The a-Si : H obtained has the usual properties of these films, low density of localized states (for instance very low spin density $\left.<10^{17} / \mathrm{cm}^{3}\right)$, high resistivity $\left(10^{9} \Omega . \mathrm{cm}\right.$ to $\left.10^{12} \Omega . \mathrm{cm}\right)$ high activation energy for its electrical conductivity $(>0.71 \mathrm{eV})$. Its hydrogen concentration $(\gtrsim 13 \%)$ and its distribution between the various sites has been described previously [6].

The a-Si films have a room temperature resistivity around $750 \Omega . \mathrm{cm}$ and a spin density $\sim 10^{20} / \mathrm{cm}^{3}$, normal for these films [5].

Here, we deposit first a $2500 \AA$ thick film of a-Si, then a $2500 \AA$ thick film of a-Si : $\mathrm{H}$ without destroying the vacuum at a deposition rate of $70 \AA / \mathrm{min}$ on $\mathrm{n}^{+} \mathrm{c}-\mathrm{Si}$ held at $190^{\circ} \mathrm{C}$. The sample is then transferred to another vacuum chamber where we deposit by thermal evaporation a Pd spot about $100 \AA$ thick and $2 \mathrm{~mm}$ in diameter, at room temperature.

The $I(V)$ curve at room temperature recorded between $\mathrm{n}^{+} \mathrm{c}-\mathrm{Si}$ and $\mathrm{Pd}$ is shown in figure 1 on a $\log -\log$ scale. There is a linear relationship between the current and voltage, identical for both polarities and holding at least for three orders of magnitude.

This implies ohmic contacts both at the a-Si/a-Si : H and $\mathrm{a}-\mathrm{Si}: \mathrm{H} / \mathrm{Pd}$ interfaces. The ohmic behaviour is retained at lower temperatures.

We have made several other structures with various 


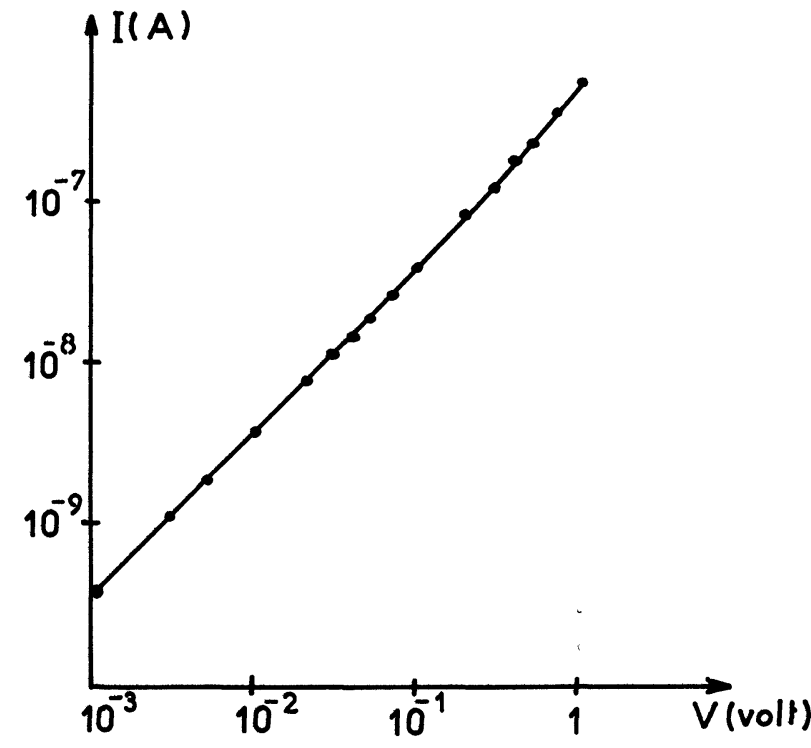

Fig. 1.

thickness of the intrinsic a-Si : H films 2 500-5 000$9000 \AA$ with thinner pure a-Si films $(\sim 1000 \AA)$. At lower thickness $(d \leqslant 3000 \AA)$, there is some decrease in the mean hydrogen content and some inhomogeneity in its distribution (see below). We find a small dispersion around a linear relationship between the conductivity and the thickness of the films (for $d>5000 \AA$ ) which indicates low contact resistance between a-Si : $\mathrm{H}$ and a-Si or $\mathrm{Pd}$ (e.g. $\rho=3 \times 10^{11} \Omega$.cm for $v=70 \AA / \mathrm{min}$ ).

We measured the total hydrogen concentration versus the depth within the sample by resonant nuclear reactions both with Boron [7] (occurring at low energy 1.8 MeV, but whose capture cross section presents a significant high energy tail needing deconvolution) and with nitrogen [8] (occurring at higher energy 6.8 MeV with no tail in its capture cross section).

The two experiments agree within the limits of experimental uncertainly. The hydrogen concentration versus depth within the film is shown in figure 2. There is first a high value of hydrogen concentration in the Pd film ( 15\%), then a hydrogen deficiency in the a-Si : $\mathrm{H}$ just neighbouring Pd, down to $\sim 7.5 \%$, then an increase to a mean value in the a-Si : $\mathrm{H}$ volume of $\sim 10 \%$. There is some inhomogeneity in the hydrogen concentration within the bulk a-Si : $\mathrm{H}$; this point will be discussed later. The hydrogen concentration then falls rapidly (within $300 \AA$ ) to about $1 \%$ in the a-Si, and then increases to a maximum value of about $2.5 \%$ before decreasing down to $\simeq 1 \%$. This non-homogeneous distribution of $\mathrm{H}$ in a-Si will also be discussed later. The first important result is the easy diffusion of hydrogen from sputtered a-Si : $\mathrm{H}$ to adjacent films at low temperature $\left(190^{\circ} \mathrm{C}\right.$ for a-Si, room temperature for $\mathrm{Pd}$ ). Another multilayer structure a-Si/a-Si $: \mathrm{H} / \mathrm{Pd}$ deposited in the same conditions with the same film thicknesses

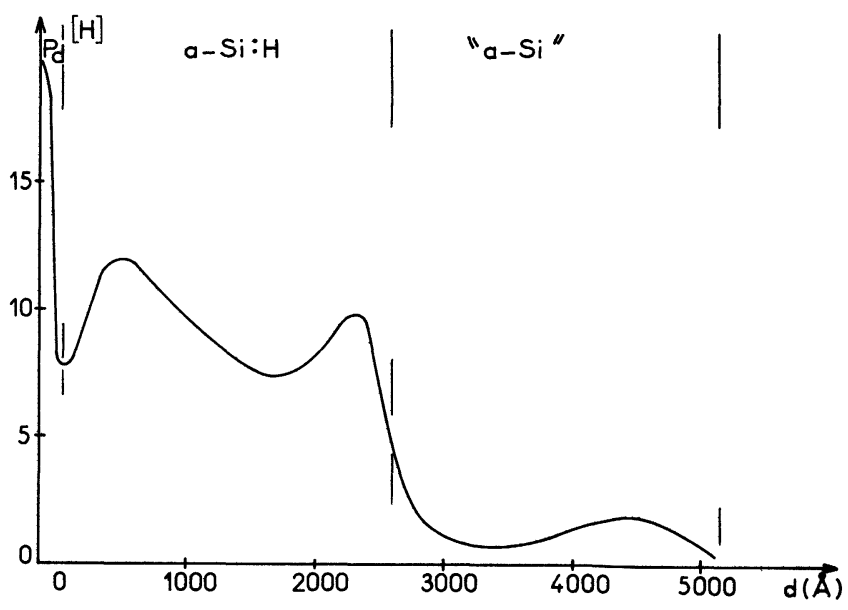

Fig. 2.

exhibits similar distribution of hydrogen in the various films which is therefore considered as reproducible.

A previously measured value for the diffusion coefficient of deuterium from a-Si/-D to a-Si : $\mathrm{H}$ was very low [9]. This value was obtained on glow discharge layers and obtained from very low deuterium concentrations.

Other experimental results on hydrogen exodiffusion [10] and low temperature hydrogenation [11] support an easy exchange of hydrogen between similar sputtered films and external media. Our films contain $5 \%$ argon and a silicon concentration around $90 \%$ of that existing in the silicon crystal, which does not change significantly with annealing up to $400{ }^{\circ} \mathrm{C}$. Annealing induces hydrogen exodiffusion [10] with very low activation energy $(0.03$ to $0.4 \mathrm{eV}$ depending on the initial hydrogen content) from $\mathrm{SiH}$ or $\mathrm{SiH}_{2}$ sites. These films can also increase their hydrogen content [11] and vary the distribution among the $\mathrm{SiH}$ and $\mathrm{SiH}_{2}$ sites by low temperature $\left(190^{\circ} \mathrm{C}\right)$ annealing in an argon-hydrogen plasma.

The hydrogen concentration in the a-Si : $\mathrm{H}$ film decreased from $\simeq 13 \%$ for a single a-Si : $\mathrm{H}$ film deposited on crystalline silicon to a mean value around $10 \%$ when this film is sandwiched between $\mathrm{Pd}$ and a-Si films. The hydrogen went to a-Si (same thickness) which was pumped 2 to $3 \%$, to $P d$, and perhaps outside through the $\mathrm{Pd}$ film.

Our previous work $[6,10,11]$ emphasize the connection between the silicon matrix and hydrogen behaviour in the material i.e. between the relative positions of the silicon atoms in a-Si : $\mathrm{H}$ and the total hydrogen content and its distribution between the various sites. Hydrogen exodiffusion out of the material as well as hydrogen entrance into the material needs a local rearrangement of the silicon matrix which restricts their extension. The possibility for the matrix to rearrange depends on the local environment, and so will not be the same near the various interfaces as in the bulk material. Hence we expect the possibility of local inhomogeneity for hydrogen 
concentration in various a-Si : $\mathrm{H}_{\boldsymbol{x}}$ matrixes in the vicinity of the interfaces from differences in rearrangement capability of the $\mathrm{Si}$ matrix.

Experimentally, we found, for instance, higher hydrogen concentration near the interface a-Si : $\mathrm{H} /$ air both for hydrogen exodiffusion [10] and entrance [11], although the hydrogen concentration appears usually uniform in the as-grown a-Si : $\mathrm{H}$ films. The inhomogeneities after hydrogen exit towards pure a-Si or $\mathrm{Pd}$ are here emphasized by the similar thicknesses of the a-Si : $\mathrm{H}$ and a-Si films.

Finally these good ohmic contacts allow us to study both conductivity versus temperature for intrinsic a-Si : $\mathrm{H}$ in sandwich structure and the behaviour of various intrinsic a-Si : $\mathrm{H}$ based devices. The thickness of a-Si is reduced to $500-1000 \AA$, and that of a-Si : $\mathrm{H}$ is increased to $9000 \AA$, to keep the concentration of hydrogen and its homogeneity within the main part of the depth as in virgin as-grown films. We find room temperature conductivities in the range $10^{-9}$ to $10^{-12} \Omega . \mathrm{cm}^{-1}$ with activation energies in the range 0.7 to $0.9 \mathrm{eV}$ rather similar to those found by Paul et al. in sputtered films [12] and Solomon et al. [4] for glow discharge a-Si : H. With the usually quoted 0.9 to $1 \mathrm{eV}[2,13]$ height for the potential barrier at the intrinsic a-Si : H/Pt interface and $\sim 10^{17} \mathrm{~cm}^{-3}$ recombination centres, we do not expect striking differences between forward and reverse $I(V)$ curves of a-Si/intrinsic a-Si : $\mathrm{H} / \mathrm{Pt}$ devices. Actually [14], although we find a space charge zone, we do not find rectifying behaviour for such structures, which brings into question the exact role of the $\mathrm{n}^{+}$ a-Si : $\mathrm{H} /$ intrinsic a-Si : $\mathrm{H}$ function in Schottky diode devices at least in sputtered materials. Schottky behaviour for $\mathrm{Pd}\left(\mathrm{a}-\mathrm{Si}: \mathrm{H}\right.$ interface with $\mathrm{n}^{+}$a-Si : $\mathrm{H}$ ) as back contact were reported mainly for glow discharge a-Si $: \mathrm{H}[2,3,13]$. As discussed above, very low diffusion coefficients for hydrogen in these materials have been claimed [9], several orders of magnitude lower than the values estimated, from various experiments, in our sputtered films $\left(D \sim 10^{-13} \mathrm{~cm}^{2} \mathrm{~s}^{-1}\right.$ at $190{ }^{\circ} \mathrm{C}$ instead of $\sim 10^{-7}$ for interstitial hydrogen in

$$
\text { c-Si [15] and } \sim 10^{-18} \mathrm{~cm}^{2} \mathrm{~s}^{-1} \text { in ref. [9]) . }
$$

This might prevent a sufficient amount of hydrogen exodiffusion from a-Si : $\mathrm{H}$ to Pd to modify the electrical behaviour of this interface, although Schottky diodes are very sensitive to surface states which often control their potential barrier. In any case the distribution of hydrogen near this interface was never reported or discussed.

Rectifying behaviour [16] has been claimed for $n$ a-Si : $\mathrm{H}$ sputtered on molybdenum using $\mathrm{NiCr}$ as low resistance (non ohmic) back contact. Without a semi-log plot of $I(V)$ and its temperature dependence, it is difficult to deduce to what extent these structures exhibit actual Schottky barrier behaviour.

Alternatively, almost all these $\mathrm{n}^{+}$a-Si : $\mathrm{H} /$ intrinsic a-Si : $\mathrm{H} /$ Metal structures use small a-Si : $\mathrm{H}$ thicknesses ( $<6000 \AA$ ), with the low density of carriers in intrinsic a-Si : H, if the back contacts are not ohmic, the corresponding band bending may be extended almost completely across the film giving $I(V)$ curves similar to those of Schottky diodes [14]

Acknowledgments. - The authors acknowledge D. Kaplan for suggesting that a-Si might be used to prepare ohmic contacts with a-Si : H, C. Bianchin and $H$. Matraire for their technical support, M. Toutlemonde, R. Danielou and J. Fontenille for nuclear measurements and the C.O.M.E.S. for financial support under the contract A 650-5106.

\section{References}

[1] e.g. Spear, W. E. and Lecomber, P. G., Philos. Mag. 33 (1976) 935

[2] e.g. Wronski, C. R., Carlson, D. E. and Daniel, R. E., Appl. Phys. Lett. 29 (1976) 602, Wronski, C. R. and Carlson, D. E., Proc. 7th. Int. Conf. Am. Liq. S.C., Edimburgh (1977).

[3] Deneuville, A. and Brodsky, M. H., Thin Solid Films 55 (1978) 137

[4] Solomon, I., Dietl, T. and Kaplan, D., J. Physique 39 (1978) 1241.

[5] Brodsky, M. H., Title, R. S., Weiser, K. and Pettit, G. D., Phys. Rev. B1 (1970) 2632.

[6] Bruyere, J. C., Deneuville, A., Mini, A., Kanil, H., DanieLOU, R., J. Appl. Phys. (in press).

[7] Ligeon, E. and Guivarch, A., Radiat. Eff. 22 (1974) 101

[8] Lanford, W. A., Trawetter, J. P., Ziegler, J. F. and Keller, J., Appl. Phys. Lett. 28 (1976) 566.
[9] Carlson, D. E. and Magee, C. W., Appl. Phys. Lett. 33 (1978) 81.

[10] Bruyere, J. C., Deneuville, A., Mini, A., Danielou, R., Ligeon, E., Proc. 8th Int. Conf. Am. Liqu. S.C., Cambridge, Mass. (August 1979).

[11] Bruyere, J. C., Deneuville, A., J. Physique Lett. 41 (1980) L-31.

[12] Anderson, D. A., Moustakas, T. D. and Paul, W., Proc. 7th Int. Conf. Am. Liqu. S.C., Ed. by W. E. Spear (C.I.C.L. University of Edimburgh) 1977.

[13] Deneuville, A., Brodsky, M. H., J. Appl. Phys. 50 (1979) 1414.

[14] Deneuville, A., Bruyere, J. C., Mini, A., Hamdi, H., Hakil, H., unpublished.

[15] Van Wieringen, A. and Warmoltz, N., Physics 32 (1956) 849.

[16] Paul, W., Lewis, A. J., Connell, G. A. N. and MoustaKAS, T. D., Solid State Commun. 20 (1977) 969. 